\title{
Impact of Distributed Generation and Series FACTS Compensator on Directional Overcurrent Protection Coordination
}

\author{
Lazhar Bougouffa and Abdelaziz Chaghi \\ LSP-IE Laboratory Research Laboratory, Faculty of Technology, Department of \\ Electrical of Engineering, University of Batna, 05000 - Algeria \\ blazhar2010@gmail.com,az_chaghi@univ-batna.dz
}

\begin{abstract}
Protection system is used to protect components against fault as fast as possible and also to minimize the area around it from fault. Nowadays because of the existence of Distributed Generation in power system, a change is needed to be implemented for protection system at distribution network in order to ensure the electricity can be supplied to the consumer safely. With the presence of distributed generation $(D G)$ units in distribution systems, the function of relay protection is generally going to be changed. In this paper the impact of installing Distributed Generation in radial system on the directional-over-current protection relay, in presence of a Thyristor Controlled Series Capacitor on fault courant is investigated. The relays coordination scheme was developed throug handysis for three fault location scenarios. A realistic feeder system for a case study with its schene protection is developed in Matlab software environment.
\end{abstract}

Keywords: Power System, Distrbuted Generation, TCSC, IDMT, Over-current Relay, Fault Current, Operation Time

\section{Introduction}

The worldwide demand for electricity continues to grow even as energy conservation measures and advances in power conversion efficiency reduce the consumption of individual loads. To feed the energy appetite of the world, renewable energy technologies are becoming feasible and offer alternative generation options that enable consideration of the impact on the environment and other social and economic factors [1].

The addition of distributed generation (DG) to the electrical distribution system has been one of the key drivers in the evolution of distribution system analysis tools over the last 15 years. Three-phase circuit modeling and other advanced features have been added to accommodate the needs of DG modeling.

Introducing DG into existing systems requires to be carefully integrated with the power system s operating practices [1]. The key concerns include:

- Voltage rise and regulation,

- Voltage fluctuations,

- Protective relaying and control functions,

- Impact on short-circuit analysis,

- Impact on fault location and clearing practices,

- Need for an interconnection transformer,

- Transformer configuration,

- Harmonics, 
- Response to system imbalances such as open-conductor faults due to failing splices.

The main objective of this study is to investigate the effect on fault current when installing distributed generation on a radial system, the effect on the inverse definite minimum time (IDMT) over-current relay in the presence of compensating series FACTS devises i.e. Thyristor Controlled Series Capacitor (TCSC).

\section{Distribution System Description}

Distributed generation (DG) apply to the notion of generating power using a set of small sized generators that produces power at low voltage levels and usually uses alternative fuel. Distributed generators have been categorized as micro $(\sim 1 \mathrm{~W}<5 \mathrm{~kW})$, small $(5 \mathrm{~kW}<5 \mathrm{MW})$, medium $(5 \mathrm{MW}<50 \mathrm{MW})$, and large $(50 \mathrm{MW}<300 \mathrm{MW})$. The DGs are mainly designed to be connected directly to the distribution network near load centres. There are several types of DGs in the market. Some are conventional such as the diesel generators and solme are new technologies such as the micro-turbines. The major DG alternatives are described briefly in the reference [2].

\section{Directional Overcurrent Relay Coordination}

The current/time tripping characteristics of IDMT (Inverse Definite Minimum Time) relays may need to be varied according to the tripping time required and the characteristics of other protection devices used in the network. For these purposes, IEC 60255-3 defines a number of standard characteristics to find the overcarrent relays operating times which is defined by the equation 1 [3]. Different characteristics are-indicated in Figure 1.

Typically, the inverse time over-urrent relay (OCR) consists of two elements, an instantaneous unit, and a time dependent unit. The time dependent unit has two values to be set, the pickup current value $\left(I_{P}\right)$, and the time dialsetting (TDS). The pickup value is the minimum current value for which the relay operates and the time dial setting defines the operating time (T) of the device for each current value. Normally, the characteristics of the directional overcurrent relay are given as a curve of (T) versus $(\mathrm{M})$, where $\mathrm{M}$ (multiple of pickup current) is the ratio of the relay current, (I), to the pickup current value, $\left(I_{P}\right)[4]$.

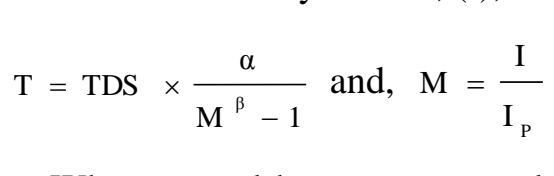

Where, $a$ and $b$ are constants depending on the type of selected characteristics: Standard Inverse (SI), Very Inverse (VI) or Extremely Inverse (EI).

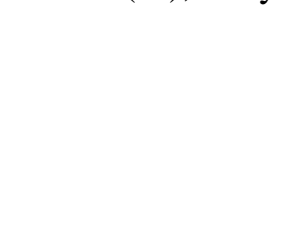




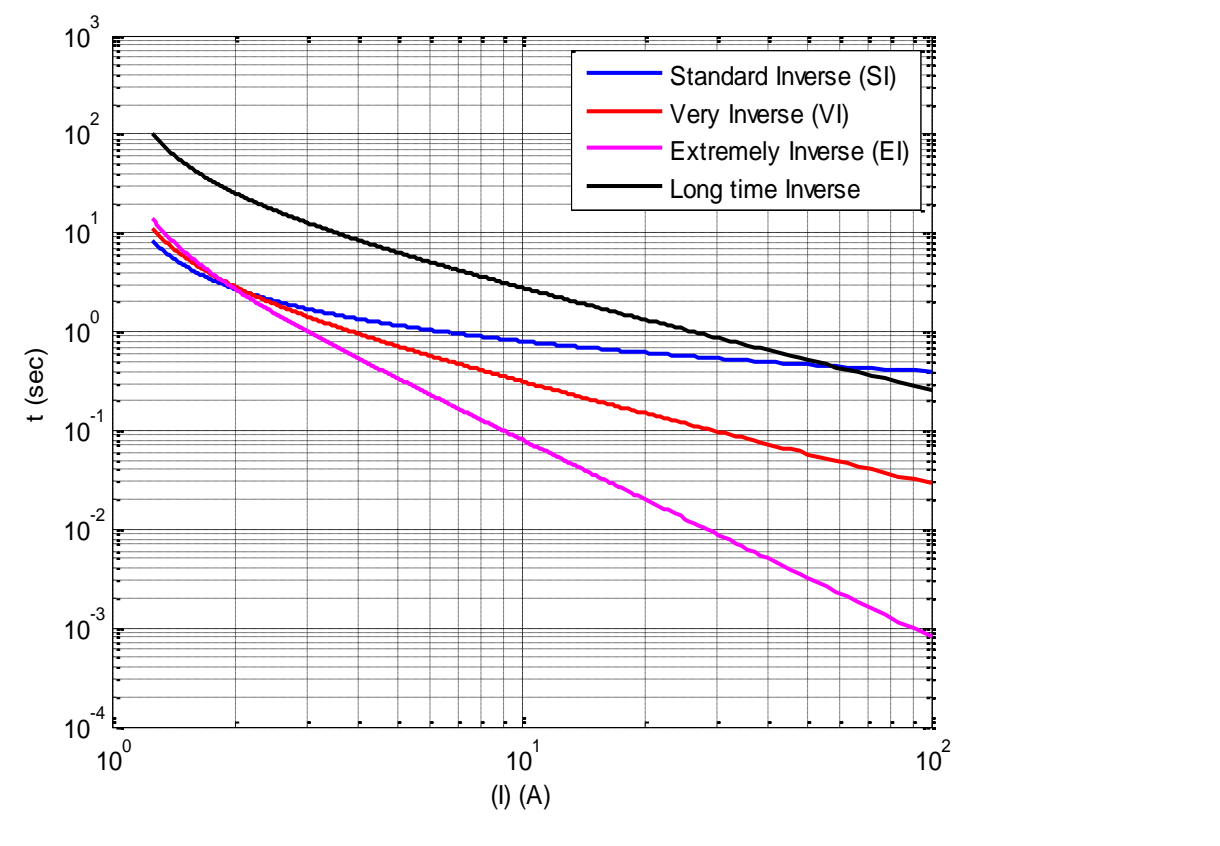

Figure 1. IDMT Relays Characteristics

\subsection{Backup-primary Constraint}

Each relay's pickup current has minimum and maximum values as shown in equation (3). These values are chosen to be 12 and 2 times the maximum load current which is seen by each relay in a normal operation Similarly, the time delay setting has a minimum and a maximum limit based on the relay's currentime characteristic. The minimum and maximum TDS are assumed to be 0.05 and 1.2 respectively in all over studies [5].

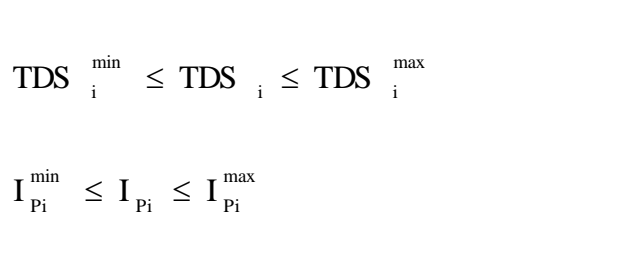

The minimum pickup current setting of the relay $\left(\mathrm{I}_{\mathrm{Pi}}{ }^{\mathrm{min}}\right)$ is the maximum value between the minimum available current setting and the maximum load current $\max \left(\mathrm{I}_{\text {loadi }}{ }^{\text {max }}, \mathrm{I}_{\mathrm{Pi}}{ }^{\mathrm{min}}\right)$. Similarly, the maximum pickup current setting $\left(\mathrm{I}_{\mathrm{Pi}}{ }^{\mathrm{max}}\right)$ is chosen as the minimum value between the maximum available current setting of the relay and the minimum measured fault current $\max \left(\mathrm{I}_{\text {Faulti }}^{\min }, \mathrm{I}_{\mathrm{Pi}}{ }^{\max }\right)$ [6].

In opder to coordinate two over-current relays, one as main (primary) relay (i) and the other as backup relay ( $\mathrm{j}$ ), the difference between the operating time of backup relay and main relay should be more than the CTI (Coordination Time Interval). The constraints coordination of overcurrent relays $i$ and $j$ will is in the form of inequality (4) [7]:

$\mathrm{T}^{\mathrm{K}}{ }_{\mathrm{j}}-\mathrm{T}^{\mathrm{K}}{ }_{\mathrm{i}} \geq \mathrm{CTI}$

$\mathrm{T}_{\mathrm{j}}^{\mathrm{K}}$ and $\mathrm{T}_{\mathrm{i}}^{\mathrm{K}}$ : are respectively the operation time of backup and primary relay for a short circuit at $\mathrm{k}$. 
CTI is the time interval coordination of primary and backup relay and it can take a value between 0.2 and 0.5 seconds, it depends on the type of relays and generally is taken as $0.3 \mathrm{sec}$ [8-9].

\section{Effect of TCSC on Directional Overcurrent Relays Setting}

The basic Thyristor Controlled Series Capacitor scheme, proposed in 1986 by Vithayathil with others as a method of "rapid adjustment of network impedance," is shown in Figure 2. It consists of a series compensating capacitor shunted by a Thyristor Controlled Reactor [10$11]$.

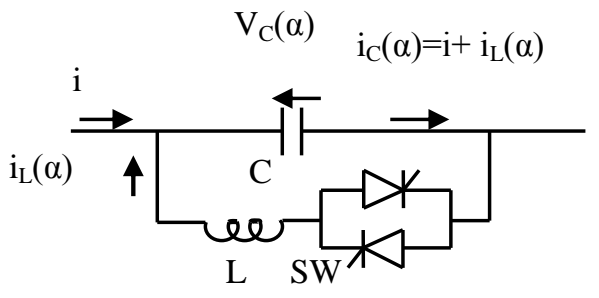

(a)

(b)

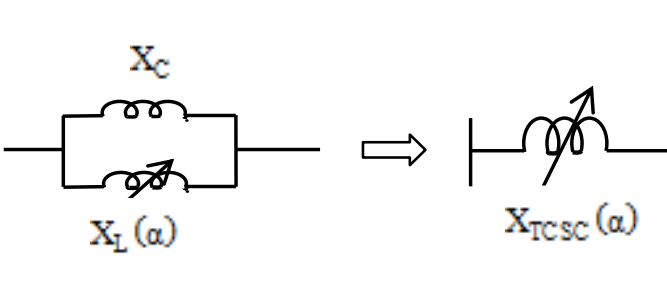

Figure 2. Principal of TCSC

(a) Basic TCSC Scheme and (b) Apparent Reactance of the TCSC

The simpler TCSC mode exploits the concept of a variable series reactance given by.

$X_{T C S C}(\alpha)=\frac{X_{L}(\alpha) \times \hat{X} \alpha}{X_{L}(\alpha)+X_{C}}$

$X_{L}(\alpha)=X_{L} \times \frac{\pi}{2 \alpha-\sin \alpha}, \mathbb{Q} \leq X_{L}(\alpha) \leq \infty$

Where,

$X_{L}=L . \omega$ and $X_{C}=\frac{1}{C . \omega}$

The equivalent TCSC reactance is computed as:

$X(\alpha)=X_{C}-\frac{X_{C}^{2}}{\left(X_{C}-X_{L}\right)} \times \frac{2 \beta+\sin (2 \beta)}{\pi}+\frac{4 X_{C}^{2}}{\left(X_{C}-X_{L}\right)} \times \frac{\cos ^{2} \beta}{\left(K^{2}-1\right)} \times \frac{(K \tan K \beta-\tan \beta)}{\pi}$

Where: $\beta=\pi-\alpha$ is the conduction angle.

"K" is a Compensation degree 
$K=\sqrt{\frac{X_{C}}{X_{L}}}$

The TCSC can be installed anywhere in the distribution circuit in order to control the power flow as a function of its capacitive-reactance. Since it is essentially a variable reactance, its impedance will be added arithmetically to the system impedance and result in a reduction of the fault currents.

\section{Simulation Results}

This section presents a computer simulation studies developed with MATLAB software to demonstrate the effect of the DG and the TCSC on fault current and on the coordination of IDMT overcurrent relays.

The 4-bus radial test system shown in Figure 3 is employed to conduct the coordination studies [12]. Detailed parameters of this system can be found in the Appendix.

The short-circuit current is a function of the voltage and the impedance of the distribution system. In order to calculate the short-circuit current for the same voltage level; the first is done by adding shunt impedance of DG, the second by insertion of series variable reactance of TCSC.

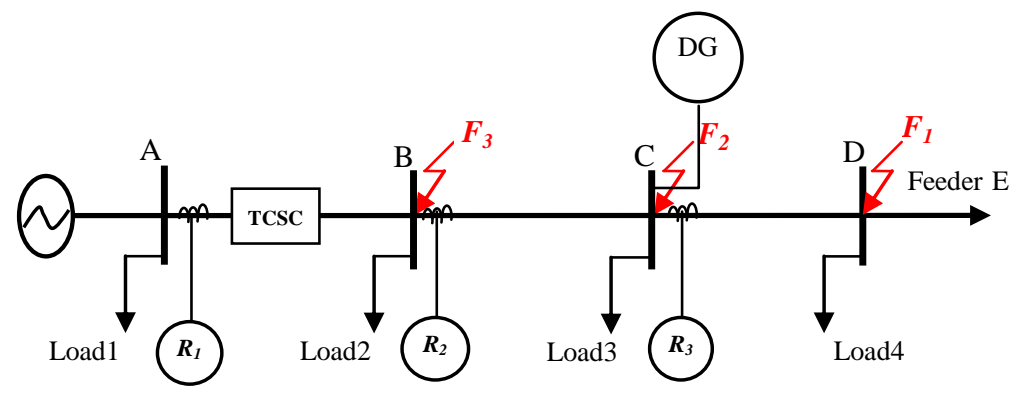

Figure 3. Simple Distribution Network with Three DG Units and a TCSC

Based on the effective TCSC reactance model given in (8), Figure 4 shows the characteristic curve of the reactance of the TCSC with respect to the firing angle $(\alpha)$. The data used for the simulation is given in Appendix.

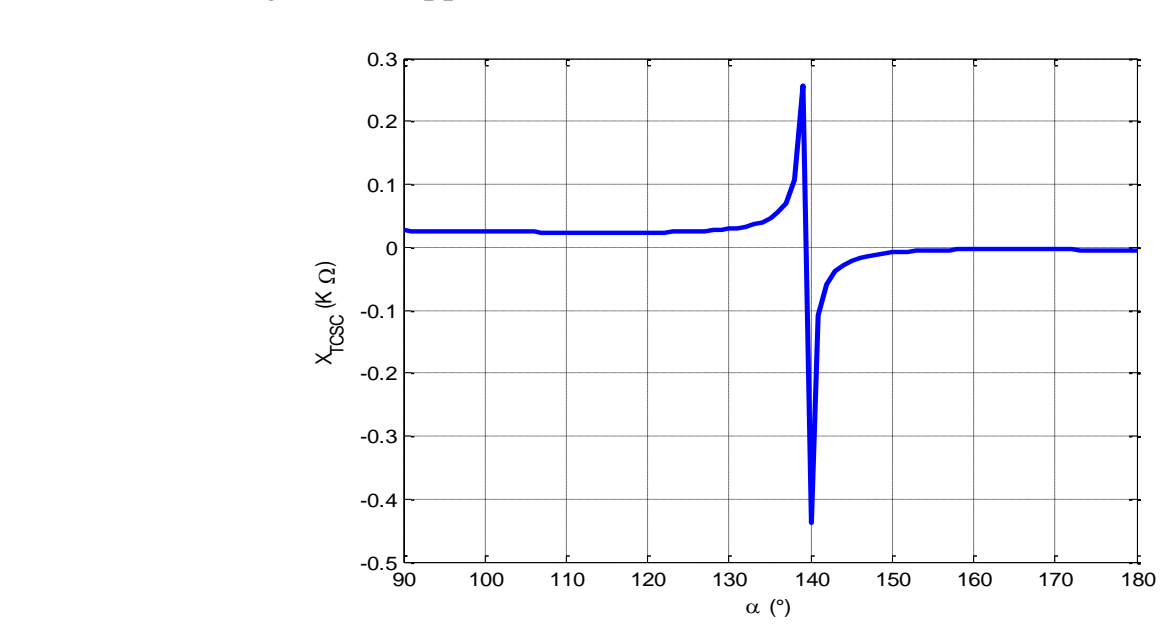

Figure 4. Characteristic Curve $X_{\mathrm{TCSC}}(\alpha)$ of the TCSC 
To coordinate overcurrent relays, as soon as a fault takes place, the fault is sensed by both primary and backup protection. The primary relay is the first to operate, as its operating time is less than that of the backup relay. A relay protection scheme in a simple radial feeder with 4 bus-bars (bus-A, bus-B, bus- $\mathrm{C}$ and bus-D) is shown in Figure 3. For a fault at point F1, relay R3 is the first to operate. If the operating time of R3 is set to 0.2 second, then the relay $\mathrm{R} 2$ should wait for 0.2 second plus a CTI.

\subsection{Impact on Short Circuit Level}

Short circuit level description is based on impact of fault on power and current. This description is criterion factor for increasing definition in fault and current. Fault level can be formulated simply as below:

$$
\mathrm{I}_{\mathrm{F}}=\frac{\mathrm{V}}{\mathrm{Z}_{\mathrm{th}}}
$$

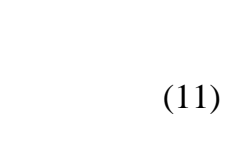

In this equation, $I_{F}$ is the fault current and $Z_{T h}$ is the Thevenin impedance seen by bus $i$. Installing DG leads to placing impedance in parallel with a part of network, therefore the impedance seen at fault location is reduced [5].

When only DG is connected, relays $R_{2}$ and $R_{3}$ will sense the downstream current for faults in Bus-D.

It is important to note here that for any given downstreanCon upstream fault, these relays will sense the same fault current, as shown ir Figures 5, 6 and 7, this result will create a conflict as these relays sense the same current for clearing either of these faults, and it is possible to achieve coordination with the pairs of relays.

Because it is required to clear only the faulted section, $R_{3}$ must operate before $R_{2}$ for fault in Bus-D, and $R_{2}$ must operate before $\mathrm{R}_{1}$ for a fult Bus-C. Relays $R_{3}$ and $R_{2}$ cannot isolate the fault in Bus-B because the zone of telays $R$

The fault is simulated by switching-on the impedance $\mathrm{Z}_{\mathrm{DG}}$ at bus-C as shown in Figure 3 . Figures 5 show the Variation of the fault currents curves as function of the angle $\alpha$ of the TCSC for three fault location.

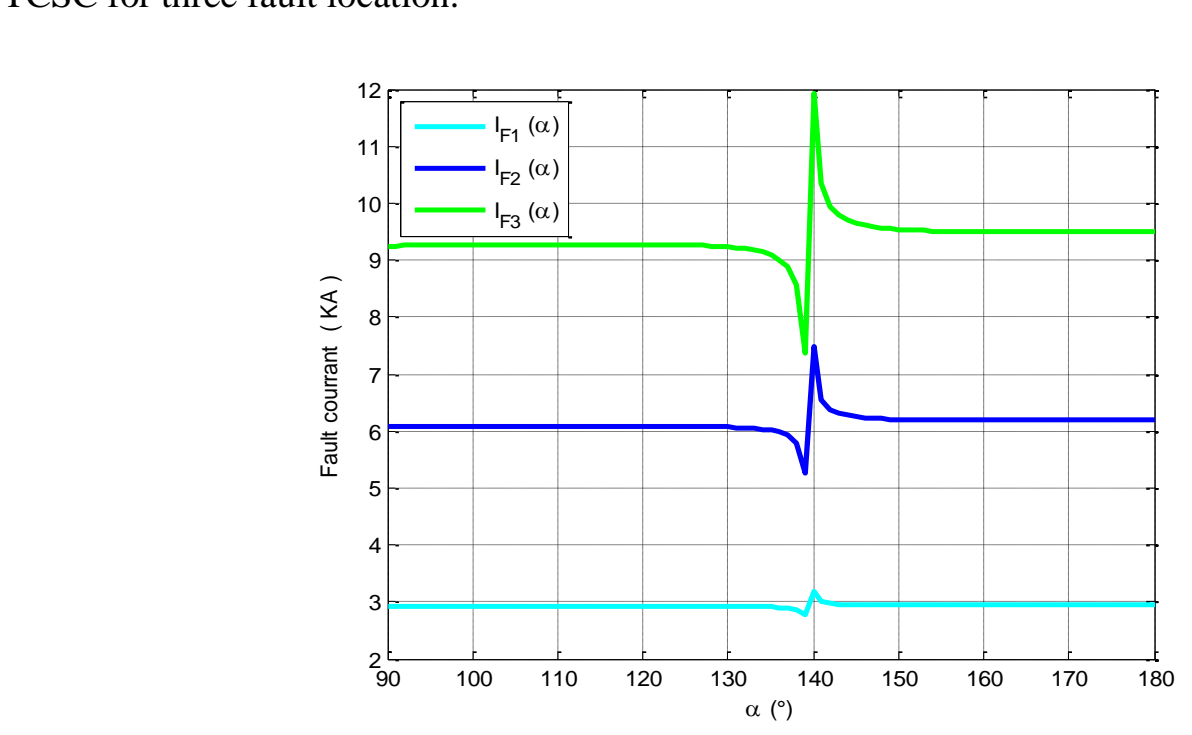

Figure 5. Variation of the Fault Currents Curves as a Function of the Angle $\alpha$ Of the TCSC at each Lcation 
From the obtained results of faults current it can be observed that, the short circuit level increases with the DG installed in the system. The short circuit level in the first case (Fault at Bus-bar D) without DG is $\mathbf{1 0 . 3 0 6 8}$ KA but after installing the DG the current becomes 10.3773 KA, it is larger than the previous because of the effect of the DG source in the second case.

The TCSC can be installed anywhere in the distribution circuit in order to control the power flow as a function of its capacitive-reactance. Since they are essentially a variable reactance, their impedance will add arithmetically to the system impedance and result in a reduction of the fault currents. That is clear in figure 5, with DG, and with the presence of Thyristor Controlled Series Capacitor (TCSC) the three phase fault current increases in inductive mode and decreases in capacitive mode.

\subsection{Impact on the Operation Time of the Overcurrent Relay}

In the network shown in Figure 3, relay 2 will act as the backup of relay 3 for the fault $F 1$, and relay 1 will act as the backup of relay 2. As for relay 2, if a fault happen in bus-D, its operation time should be larger than that of relay 3 at least by the CTI. Figure. 6 shows a selectivity diagram of relays R3 and R2 for a fault located at Bus-bar D.

The presence of DG and TCSC will change the normal power flow as well as the shortcircuit current, which are not restricted to the connected bus. Figure.6 shows as well the primary/backup (P/B) relay pairs and corresponding operating times for the fault currents passing through them in presence of the DG at Bus-bar C and TCSC Installed in middle of branch $\mathrm{AB}$.

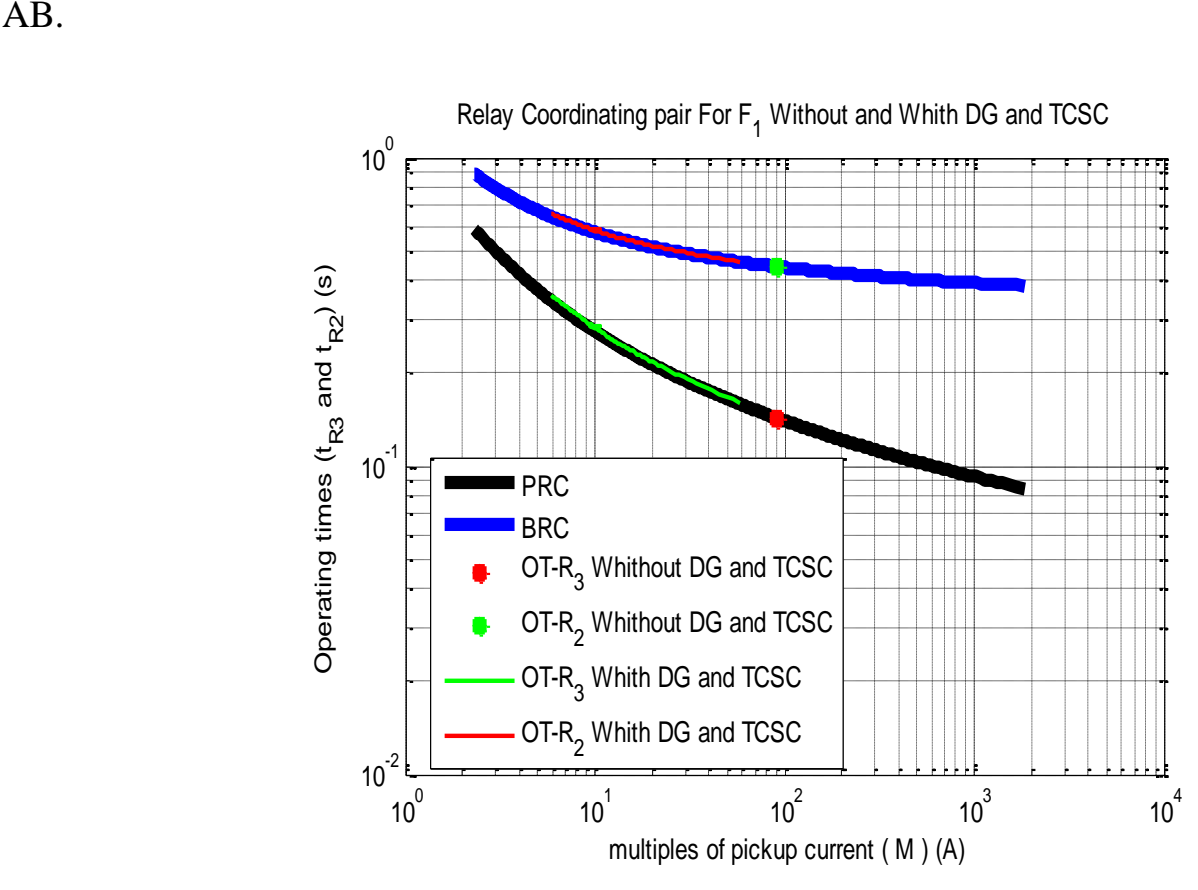

Figure 6. Operating Times Characteristics of Primary and Backup Relays for Fault located at Bus-bar D Without and with DG and TCSC

Figure shows R1 providing backup to relay R2 and their respective operating time. 


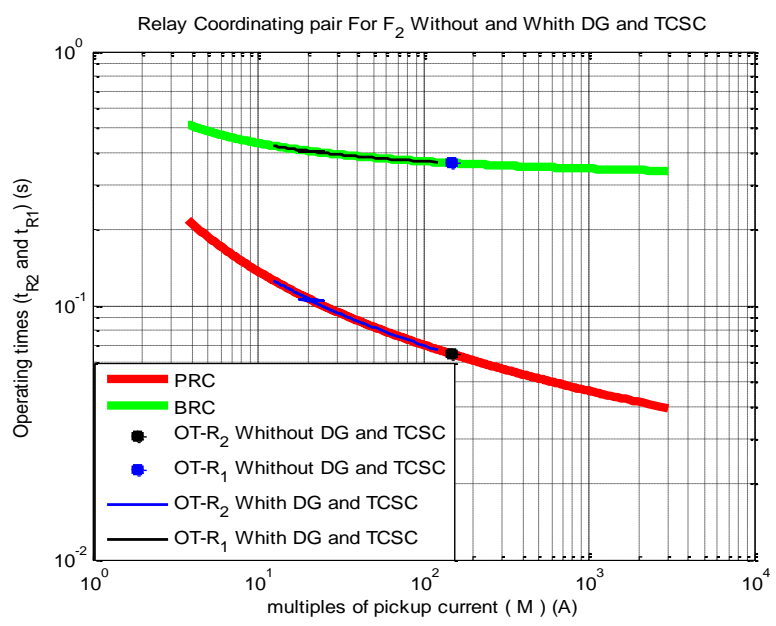

Figure 7. Operating Times Characteristics of Primary and Backup Relays for Fault Located at Bus-bar C Without and with DG and TCSC

Figures 8 show the operating time of R1 for a fault located at Bus-bar B

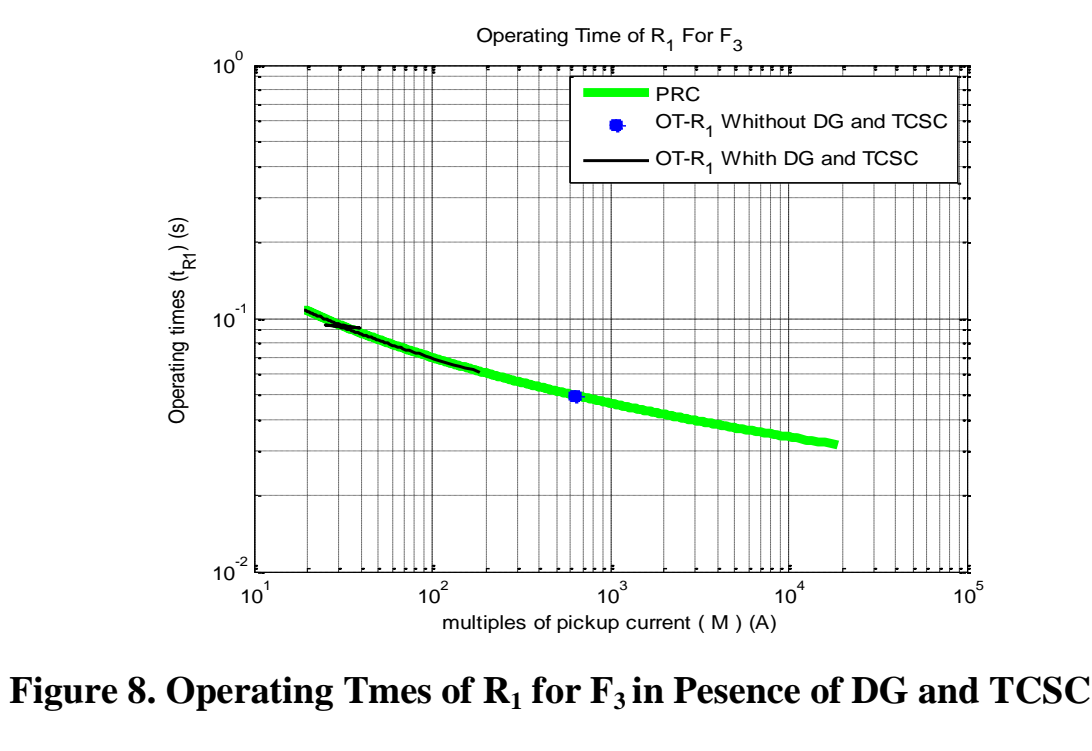

In Fgure 6, 7 and 8 PRC, BRC and OT are Primary Relay Characteristic, Backup Relay Characteristic and Operating Time respectively.

Figures 67 and 8 show that the operating times of primary and back-up relays, the operatingtimes of primary relays without TCSC are less than the operating times of primary relays in both inductive and capacitive mode, when a fault occurs at any bus of the network in the presence of the TCSC. It can be seen as well that there is an effect of the fault in both inductive and capacitive mode on the operating times.

\section{Conclusion}

The simulation results reported in this paper demonstrate that the integration of embedded DG and TCSC have an effect on the settings of IDMT overcurrent relays devices installed on the distribution feeders. In this paper the case studies have been conducted to determine the 
effect of the clearing time of a fault on any point of network. From the results it can be concluded that the presence of DG and TCSC affect the clearing time of the protective devices installed in the distribution feeders. Therefore care must be taken when DG are installed on distribution network. In future, work can be conducted on the development of an algorithm to optimize the relays operation time and revising the protection system by minimizing the number of changes in relays setting caused by the presence of the TCSC.

\section{Appendix}

Power source: $\mathrm{U}_{\mathrm{s}}=11 \mathrm{kV}, \mathrm{f}=50 \mathrm{~Hz}$.

Impedance of line: $\mathrm{Z}_{\mathrm{AB}}=0.0922+\mathrm{j} 0.0470 \Omega, \mathrm{Z}_{\mathrm{BC}}=0.4930+\mathrm{j} 0.2511 \Omega$ and $\mathrm{ZCD}=0.3660+\mathrm{j} 0.1864 \Omega$. Loads data: Load 1: $S_{1}=100+\mathrm{j} 60 \mathrm{KVA}$, Load 2: $S_{2}=90+\mathrm{j} 40 \mathrm{KVA}$, Load 3: $\mathrm{S}_{3}=120+\mathrm{j} 80 \mathrm{KVA}$ and Load 4: $\mathrm{S}_{4}=60+\mathrm{j} 20 \mathrm{KVA}$.

TCSC: $\mathrm{L}=9.60 \mathrm{mH}, \mathrm{C}=212.2 \mu \mathrm{F}$.

DG: $P_{\mathrm{DG}}=5 \mathrm{MW}, \mathrm{Z}_{\mathrm{DG}}=2.3287+\mathrm{j} 22.8855 \Omega$.

IDMT over-current relay: Relay 1, 2 and 3: Normal Inverse, TC = 1000/5.

\section{References}

[1] Smart Grid: Reinventing the Electric Power System, IEEE Powei \& Energy Society (PES), USA, www.ieeepes.org. (2012).

[2] H. Zayandehroodi, A. Mohamed, H. Shareef and M. M. jafari Impact of distributed generations on power system protection performance", International Journal of the Physical Sciences, (2011).

[3] Network Protection \& Automation Guide, Published by AREVA, Paris, France, T\&D Ltd, (2002).

[4] H. H. Zeineldin, E. F. El-Saadany and M. M.A. Salama, "Optimal coordination of over current relays using a modified particle swarm optimization", Electric Power Systens Research, (2006).

[5] H. Javadi, S. M. A. Mousavi and M. Khederzedeh, "A nowe approach to increase FCL application in preservation of over-current relays coordination in presence of asynchronous DGs", Electrical Power and Energy Systems, (2013).

[6] M. Jazaeri and M. Cholamzadeh, Considering the Effect of Series Capacitor in Optimal Coordination of Directional Over-current Relays", Trends in Applied Sciences Research, Academic Journals Inc, (2012).

[7] D. Vijayakumar and R. K. Nema, "Superiority of PSO Relay Coordination Algorithm over Non-Linear Programming: A Comparison", Reyiew and Verification, IEEE, (2008).

[8] E. Mazhar and K. Robert, A novel method for optimal Coordination of directional over-current relays considering their available discrete settings and several operation characteristics", Electric Power Systems Research, (2011).

[9] B. K. Panigrahi, M. Singh and A. R Abhyankar, "Optimal coordination of directional over-current relays using Teahing Learning-Based Pptimization (TLBO) algorithm”, Electrical Power and Energy Systems. (2013).

[10] M. Zellagui and A. Chaghi 'Impact of TCSC on Measured Impedance by MHO Distance Relay on $400 \mathrm{kV}$ Algerian Transmission Line in Presence of Phase to Earth Fault", Journal of Electrical Systems, (2012).

[11] M. Zellagui and A. Chaghi, "A Comparative Study of GCSC and TCSC Effects on MHO Distance Relay Setting in Algerian Transmission Line”, International Journal of Engineering and Technology, (2012).

[12] J. Ma, Xi Wang, Y. Zhang, Q. Yang and A. G. Phadke, "A novel adaptive current protection scheme for distribution systems with distributed generation", Electrical Power and Energy Systems, (2012).

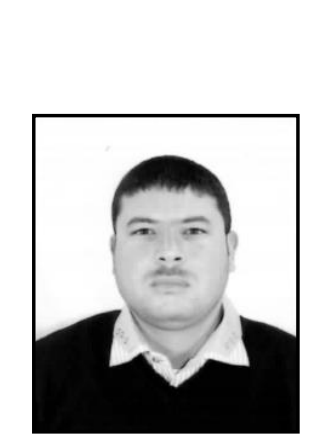

\section{Authors}

Lazhar Bougouffa, was born in Batna, Algeria, 1986. He received his MASTER degree in Electrical Engineering from department of Electrical Engineering at University of Batna, Algeria, 2011 and is currently doing PHD in Electrical power system. 


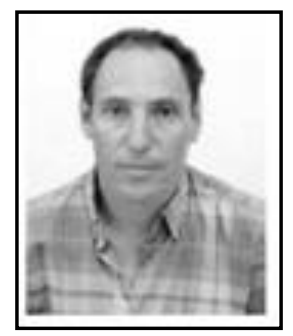

Prof. Abdelaziz Chaghi, was born in Batna, Algeria, 1954. He received his BS degree from the University of Oran, Algeria 1980, and MS from the Manchester University, En gland 1984, and received his $\mathrm{PhD}$ from Batna University, Algeria 2004. He is currently a Professor at department of Faculty of Technology, Electrical Engineering and member LSP-IE research laboratory at faculty of technology - University of Batna. His areas of interest include power systems optimisation, power system protection, renewable energy sources, harmonic, power quality and FACTS devices.

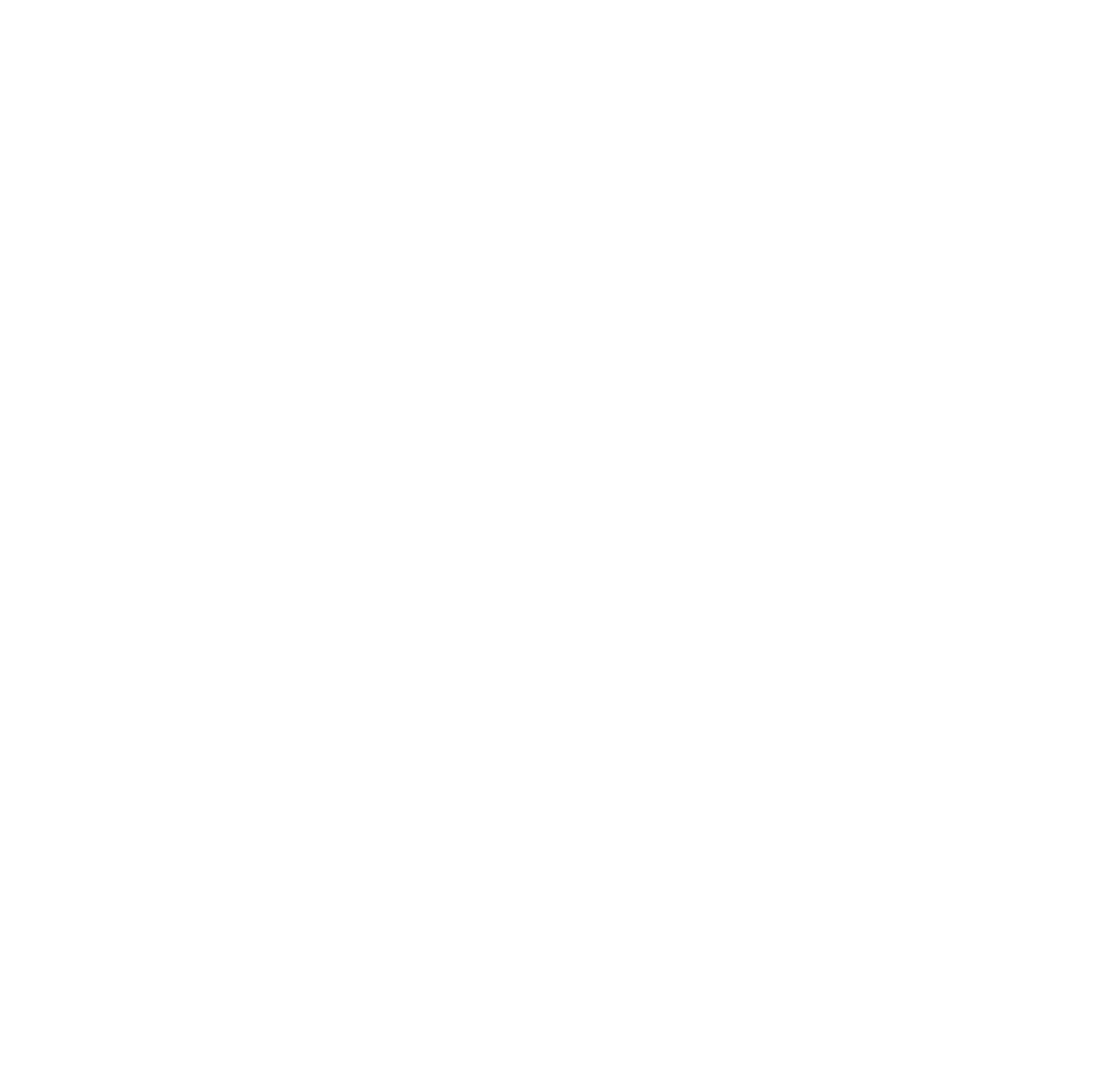

